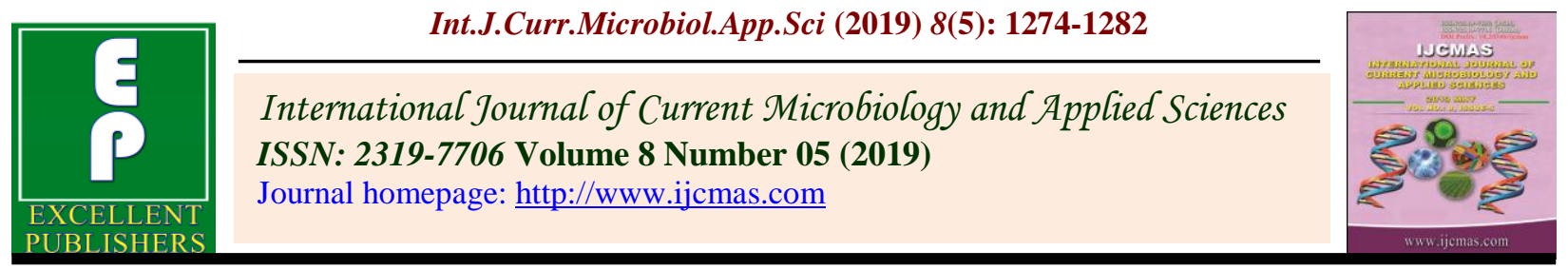

Original Research Article

https://doi.org/10.20546/ijcmas.2019.805.145

\title{
Postharvest Losses during the Marketing of Large Cardamon and Ginger Spices Crops in East District of Sikkim
}

\author{
Archana Sharma and Amod Sharma* \\ Department of Agricultural Economics, Nagaland University SASRD, Medziphema Campus, \\ District: Dimapur - 797 106, Nagaland, India \\ *Corresponding author
}

\section{A B S T R A C T}

\section{Keywords}

Postharvest losses,

Cardamon,

Ginger, Sikkim

Article Info

Accepted:

12 April 2019

Available Online:

10 May 2019
The present study on post-harvest losses during the marketing of large cardamom and ginger spices crops in the East district of Sikkim state was initiated during the year 2017 to 2019 with the selection of 80 numbers of respondents and it was categorized into three groups viz., marginal. Small and semi-medium size groups based on available cultivable land under the both selected spices crops. To achieve the specific objectives of the present study a multi stage purposive stratified random sampling method was adopted. Further data reveals that on the selected farm size group the majority of the respondents $(50.00$ per cent) belonged to small land holding with an area of 1.01 ha to 2.00 ha. The post-harvest losses incurred for large cardamom at farmer's level was found maximum on marginal with 24.83 per cent and on the overall farm size group it was found to be 20.04 per cent. The overall post-harvest losses incurred for large cardamom at wholesaler, auction and retailer level was found to be $0.0008 \mathrm{~kg}$. The post-harvest losses incurred at farmer's level were found maximum on semi-medium farmers with 3.00 per cent. While the post-harvest losses incurred at traders' level at various stages of marketing of ginger. The highest estimated loss was incurred by wholesalers with 3.00 per cent, followed by retailers with 2.80 per cent and Processors with 2.30 per cent, respectively.

\section{Introduction}

IFOAM defines organic agriculture as "a production system that sustains the health of soils, ecosystems and people. It relies on ecological processes, biodiversity and cycles adapted to local conditions instead of using inputs with adverse effects. Organic agriculture combines tradition, innovation and science to promote fair relationships and a good standard of life for all involved (IFOAM, 2000). According to the latest FiBL survey on certified organic agriculture worldwide, there were 57.81 million hectares of organic agricultural land in 2016. The regions with the largest areas of organic agricultural land are Oceania (27.32 million hectares) and Europe (13.51 million hectares). Latin America has 7.12 million hectares, Asia (4.90 million hectares), North America (3.1 million hectares) and Africa (1.8 million hectares). The countries with the most organic agricultural lands are Australia (27.4 million hectares), Argentina (3 million hectares), and China (2.31 million hectares) (Willer and Lernoud, 2018). As on $31^{\text {st }}$ March 2018, total area under organic certification process (registered under National Programme for 
Organic Production) is 3.56 million Hectare (2017-18). Madhya Pradesh has covered largest area under organic certification followed by Rajasthan, Maharashtra and Uttar Pradesh (APEDA, 2019).

Large cardamom (Amomum subulatum, Roxb) is a member of the family Zingiberacea under the order Scitaminae (Bisht et al, 2011). It is believed that Sikkim is the place of origin for cardamom (Adhikari, 2016). Nepal is the largest producer of large cardamom in the world; more than $95 \%$ of the produce is marketed to India, the largest exporter of large cardamom (Sharma et al, 2018).

Ginger (Zingiber officinale Rosc.) is cultivated in India, China, Japan, Indonesia, Australia, Nigeria and West Indies. India is the largest producer and consumer of ginger in the world (Anonymous, 2018). It is one among the regionally advantageous crops in the Northeast India. Among North Eastern States, Sikkim ranks third in area and fifth in production as well as productivity (Rahman et $a l, 2007)$.

Bhutia et al., (2017) in their paper entitled "Post-harvest and value chain management of large cardamom in hills and uplands" have mentioned that the post-harvest value chain consisted of growers, collectors, traders, and exporters. The losses in the field vary from 5.00 to 10.00 per cent which may go up to 80.00 per cent in case of disease affected materials.

India exports large cardamom to Australia, Canada, Pakistan, UK, etc. They also mentioned that Singtam, Gangtok, Jorethang, Rongli, and Mangan etc. are the major local markets in Sikkim. Siliguri is the main trade link from where it is distributed to Guwahati, Kolkata and Delhi. NERAMAC along with the Spices Board of India conducts auctions for the sale of large cardamom to provide remunerative prices to the farmers. The rate of commission charged is only 1.00 per cent. In the absence of NERAMAC the marketing of large cardamom is left solely at the hands of the middlemen of the region who have control over the prices of large cardamom. The growers have little or no idea regarding marketing and as a result they sell the produce at a much cheaper rate.

Agriculture marketing is not regulated in the state so the marketing of horticultural produce is unorganized. Largest fruits and vegetables market is Kanchenjunga Complex in Gangtok which is occupied by wholesalers and retailers. NERAMAC, SIMFED and few farmers' groups and individuals have outlets in the complex. There is no other facility available as per the APMC guideline. Government made effort to organize horticulture trade by locating it under one regulated market in East Sikkim but due to non-interest of traders it could not be implemented (Anon, 2017).

\section{Materials and Methods}

Sikkim is a small state with only four districts and sixteen sub-divisions. This state was chosen primarily due to the lack of academic research in the field of post-harvest as well as marketing of organic spices. Spices are grown in almost all the districts; however large cardamom and ginger are the two major cash crops and important source of income for the farmers in the East district of Sikkim, which is also a hub of all administrative activities. For the present study out of total eight developmental blocks two blocks were selected randomly viz., Khamdong and Regu. For the marketing cost and post-harvest activities / information altogether 10 numbers of marketing agencies were selected with the help of FPO's and Progressive organic farmers viz., 5 wholesalers and 3 retailers along with two marketing institutes viz. 
SIMFED and NERAMAC all are actively functional in the state with the help of the Assistant Managers of both the institutes.

Table 1 reveals the distribution of respondents of sample size according to the land holding size groups, the majority of the respondents (50.00 per cent) belonged to small (having an land holding of 1.01 ha to $2.00 \mathrm{ha}$ ) even the total household of the selected area is almost same, while 28.75 per cent of the respondents were of semi-medium group (having an land holding of 2.01 ha to 3.00 ha) will be same and 21.25 per cent were of marginal farm size group (having an land holding of 0.02 ha to $1.00 \mathrm{ha}$ ) is almost same to the population of household size, respectively. Similar research finding were reported by Sharma et al., (2016) and Walling et al., (2017).

\section{Post-harvest loss estimation of large cardamom and ginger at different stages of marketing}

To evaluate the post-harvest losses in the cultivation of large cardamom and ginger, Egyir et al., (2008) stated that there are no accepted methods for evaluating post-harvest losses of fresh produce whatever evaluation method used maybe due to the result referred only to a described situation.

Similar studies carried out by (Sharma and Sharma, 2008); (Pongener and Sharma, 2018).

The formula used was percentage $(\%) T Q_{L}=$ $Q / T Q \times 100$

Where as:

$\% \mathrm{TQ}_{\mathrm{L}}=$ percentage post- harvest loss per commodity.

$\mathrm{Q}=$ mean quantity loss of the commodity.

$\mathrm{TQ}=$ mean total quantity loss of the commodity.

\section{Results and Discussion}

The post-harvest losses can occur at any stage of the marketing chain, while the post-harvest losses in terms of horticultural aspects are different from economic aspects. In case of large cardamom as stated by the respondents weight or moisture loss during drying was the only loss incurred. However, moisture loss is an important aspect for drying of capsules in order to reduce bulk while marketing and cannot be considered as economic loss. Thus, there was no economic loss involved at farmer's level.

Table 2 reveals the post-harvest losses incurred for large cardamom at farmer's level was found to be maximum on marginal farm size group with 24.83 per cent, followed by 19.42 per cent on small farm size group and it was least on semi-medium farm size group with 18.77 per cent, whereas on the overall farm size group it was found to be 20.04 per cent, respectively. Similar studies carried out by Sharma (2012); Walling and Sharma (2015); Shuya and Sharma (2014); Shuya and Sharma (2018).

Table 3 reveals the post-harvest losses incurred for large cardamom at wholesaler, auction and retailer level, while it was found maximum on Auction platform with an average losses per $\mathrm{kg}$ of $0.0012 \mathrm{~kg}(0.00099$ per cent), followed by $0.0007 \mathrm{~kg}(0.00102$ per cent) on Wholesaler and it was found to be least on Retailers of $0.0006 \mathrm{~kg}$ with 0.00079 per cent, whereas on the overall / average losses was found to be 0.0008 with 0.00094 per cent, respectively. Similar studies carried out by Sharma (2011); (Sharma et al., 2016).

Table 3 reveals that the post-harvest losses incurred at different stages of marketing. The estimated loss was found to be very low at every level as large cardamom capsules are sold only after drying. The estimated loss was 
found to be highest at auction level $(0.00099$ per cent) due to the fact that farmers prefer to sell the produce only when they get satisfactory prices. The withdrawn lots are stored for a long time till the next auction takes place. Similar studies carried out by (Dharkre and Sharma, 2010).

Table 4 reveals that the post-harvest losses incurred at farmer's level at various stages of marketing of ginger. The highest estimated loss was for medium farmers (3.00 per cent), followed by small and marginal farmers (2.00 per cent) each, respectively. Similar studies carried out by Sharma et al., (2018).

Table 5 reveals that the post-harvest losses incurred at traders' level at various stages of marketing of ginger. The highest estimated loss was incurred by wholesalers $(3.00$ per cent), followed by retailers ( 2.80 per cent) and Processors (2.30 per cent), respectively. Similar studies carried out by Sharma (2012); Sharma et al., (2018).

Table.1 Selection of sample respondents on different farm size groups

\begin{tabular}{|l|l|l|l|l|}
\hline S. N. & Land holding / Category & Total house hold & Sample size & Percentage \\
\hline 1. & Marginal (0.02 to $1.00 \mathrm{ha})$ & $172(21.13)$ & 17 & 21.25 \\
\hline 2. & Small (1.01 ha to $2.00 \mathrm{ha})$ & $408(50.12)$ & 40 & 50.00 \\
\hline 3. & Semi-medium $(2.01$ ha to $3.00 \mathrm{ha})$ & $234(28.75)$ & 23 & 28.75 \\
\hline Total & & $814(100.00)$ & 80 & 100.00 \\
\hline
\end{tabular}

(Parenthesis indicate percentage to total)

Table.2 Post-harvest losses incurred for large cardamom at farmer's level

\begin{tabular}{|l|l|l|l|}
\hline $\begin{array}{l}\text { Sl. } \\
\text { No. }\end{array}$ & Farm size groups & $\begin{array}{l}\text { Average quantity of raw } \\
\text { capsules produced (Kg) }\end{array}$ & $\begin{array}{l}\text { Average quantity } \\
\text { after drying (Kg) }\end{array}$ \\
\hline 1. & Marginal & $288.57(100.00)$ & $71.64(24.83)$ \\
\hline 2. & Small & $444.70(100.00)$ & $86.37(19.42)$ \\
\hline 3. & Semi-Medium & $875.33(100.00)$ & $164.33(18.77)$ \\
\hline 4. & Overall & $536.20(100.00)$ & $107.45(20.04)$ \\
\hline & & & \\
\hline & & & \\
\hline
\end{tabular}

Table.3 Post-harvest losses incurred for large cardamom at wholesaler, auction and retailer level

\begin{tabular}{|l|l|l|l|l|}
\hline S.. No. & $\begin{array}{l}\text { Marketing/ } \\
\text { Intermediate } \\
\text { Agencies }\end{array}$ & $\begin{array}{l}\text { Average } \\
\text { quantity } \\
\text { procured }(\mathbf{k g})\end{array}$ & $\begin{array}{l}\text { Average } \\
\text { loss }(\mathbf{k g})\end{array}$ & $\begin{array}{l}\text { Estimated loss to } \\
\text { quantity procured (\%) }\end{array}$ \\
\hline $\mathbf{1 .}$ & Wholesalers & 68.58 & 0.0007 & 0.00102 \\
\hline $\mathbf{2 .}$ & Auction Platform & 121.75 & 0.0012 & 0.00099 \\
\hline $\mathbf{3 .}$ & Retailers & 75.07 & 0.0006 & 0.00079 \\
\hline $\mathbf{4 .}$ & Overall / Average & 88.47 & 0.0008 & 0.00094 \\
\hline
\end{tabular}


Table.4 Post-harvest losses incurred for ginger at farmer's level

\begin{tabular}{|c|l|c|c|c|c|c|}
\hline Sl. No. & $\begin{array}{c}\text { Farm size } \\
\text { groups }\end{array}$ & $\begin{array}{c}\text { Average } \\
\text { quantity } \\
\text { produced } \\
\text { (Kg) }\end{array}$ & $\begin{array}{c}\text { Average } \\
\text { loss (Kg) }\end{array}$ & $\begin{array}{c}\text { Price per } \\
\text { Kg } \\
\text { through } \\
\text { wholesalers } \\
\text { (Rs) }\end{array}$ & $\begin{array}{c}\text { Price per } \\
\text { kg } \\
\text { through } \\
\text { processors } \\
\text { (Rs) }\end{array}$ & $\begin{array}{c}\text { Estimated } \\
\text { loss to } \\
\text { quantity } \\
\text { produced (\%) }\end{array}$ \\
\hline $\mathbf{1 .}$ & Marginal & 760.7143 & 15.21 & 40 & 30 & 2.00 \\
\hline $\mathbf{2 .}$ & Small & 829.6078 & 16.592 & 40 & 30 & 2.00 \\
\hline 3. & Medium & 1381.333 & 41.4399 & 40 & 30 & 3.00 \\
\hline $\mathbf{4 .}$ & Average & 990.5518 & 24.41397 & 40 & 30 & 2.33 \\
\hline
\end{tabular}

Table.5 Post-harvest losses incurred for ginger at wholesaler, processor and retailer level

\begin{tabular}{|c|l|c|c|c|}
\hline Sl. No. & Particulars & $\begin{array}{c}\text { Average quantity } \\
\text { procured (Kg) }\end{array}$ & $\begin{array}{c}\text { Average loss } \\
\text { (Kg) }\end{array}$ & $\begin{array}{c}\text { Estimated loss to } \\
\text { quantity procured (\%) }\end{array}$ \\
\hline 1. & Wholesalers & 760.69 & 22.21 & 2.92 \\
\hline 2. & Processors & 700.02 & 16.10 & 2.30 \\
\hline 3. & Retailers & 760.67 & 21.29 & 2.80 \\
\hline 4. & Average & 740.46 & 19.87 & 2.67 \\
\hline
\end{tabular}

Fig.1 Trend in area, production and productivity of large cardamom in East Sikkim

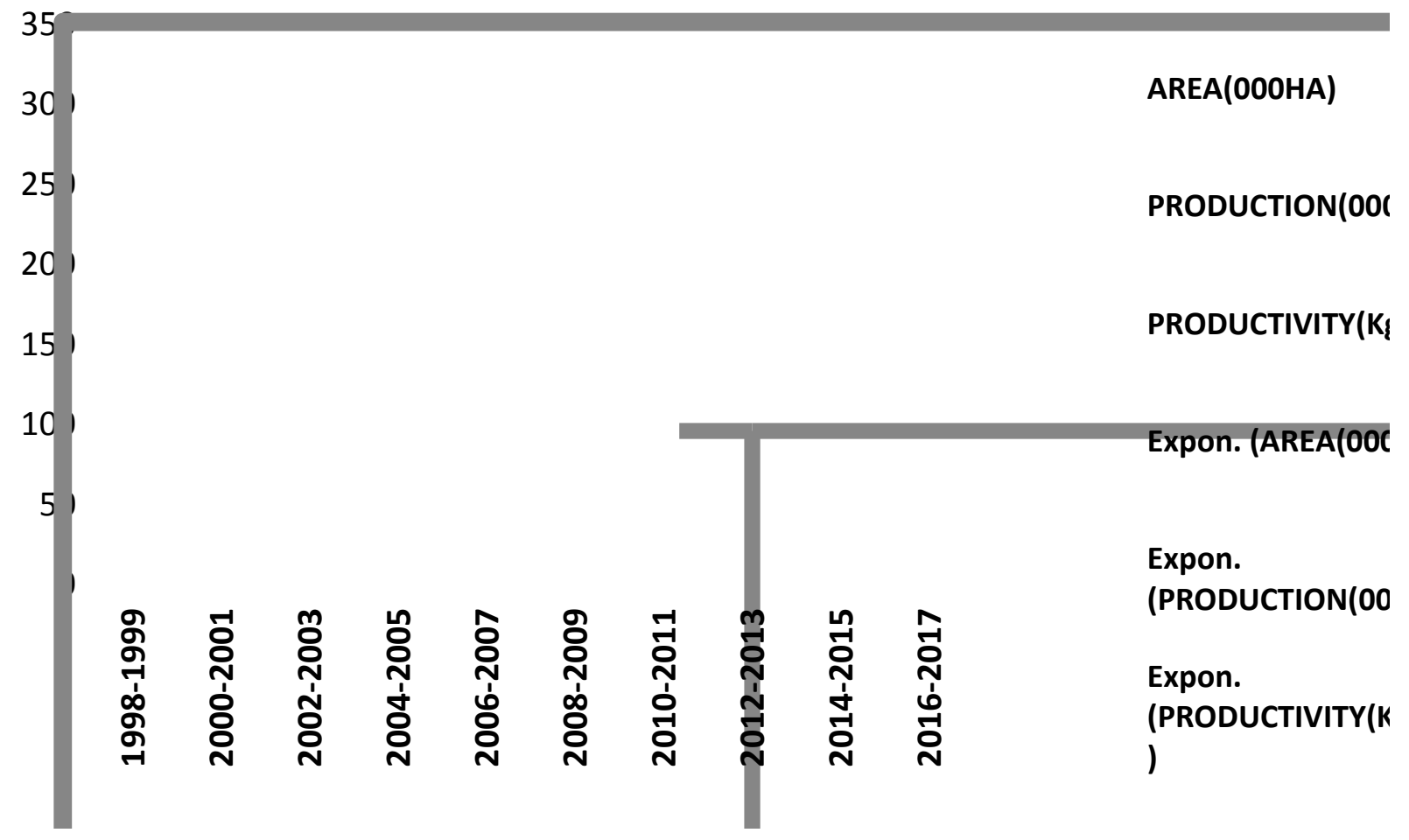


Fig.2 Trend in area, production and productivity of ginger in East Sikkim

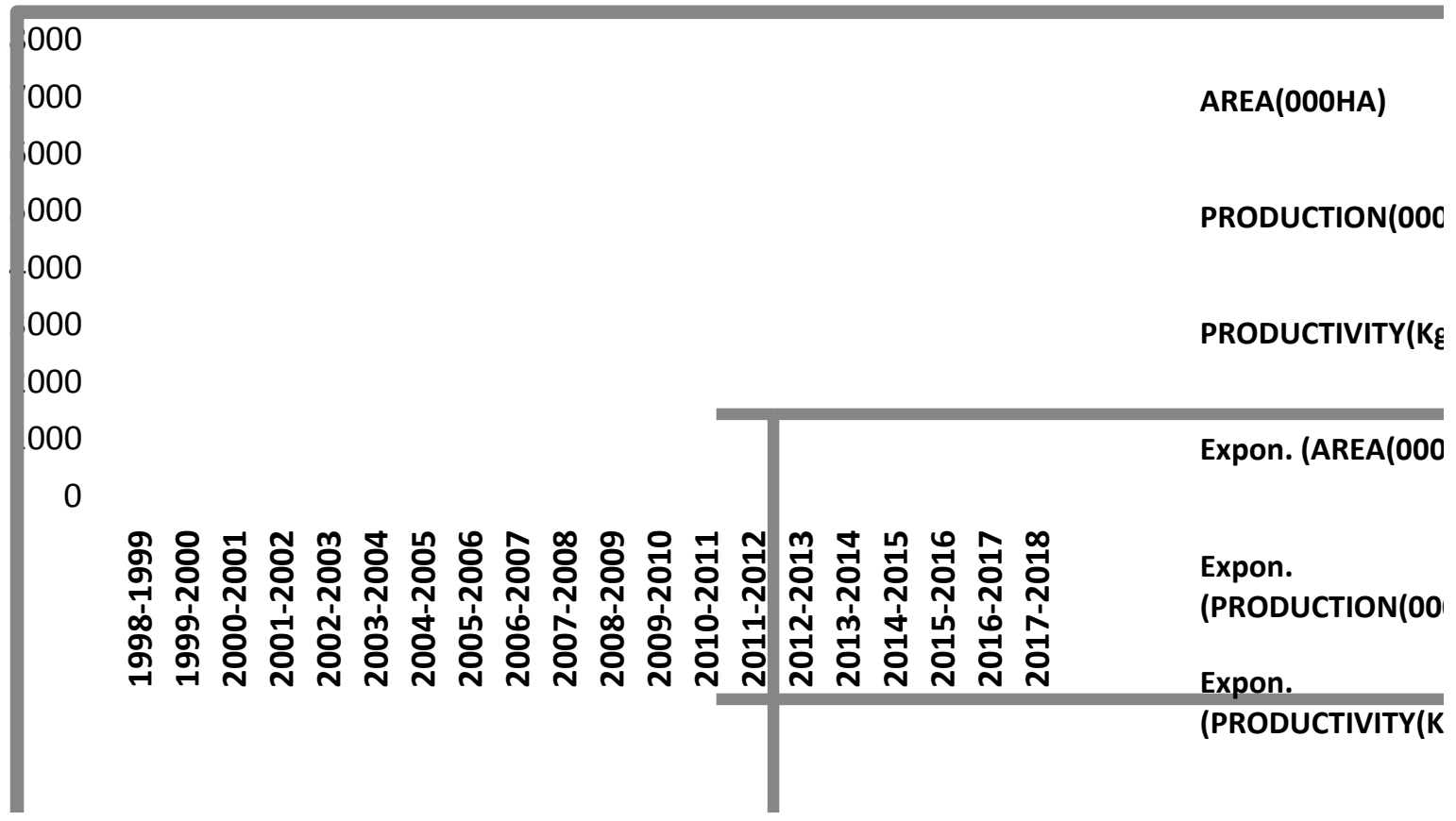

Fig.3 Estimation of post-harvest losses in large cardamom incurred at farmers level

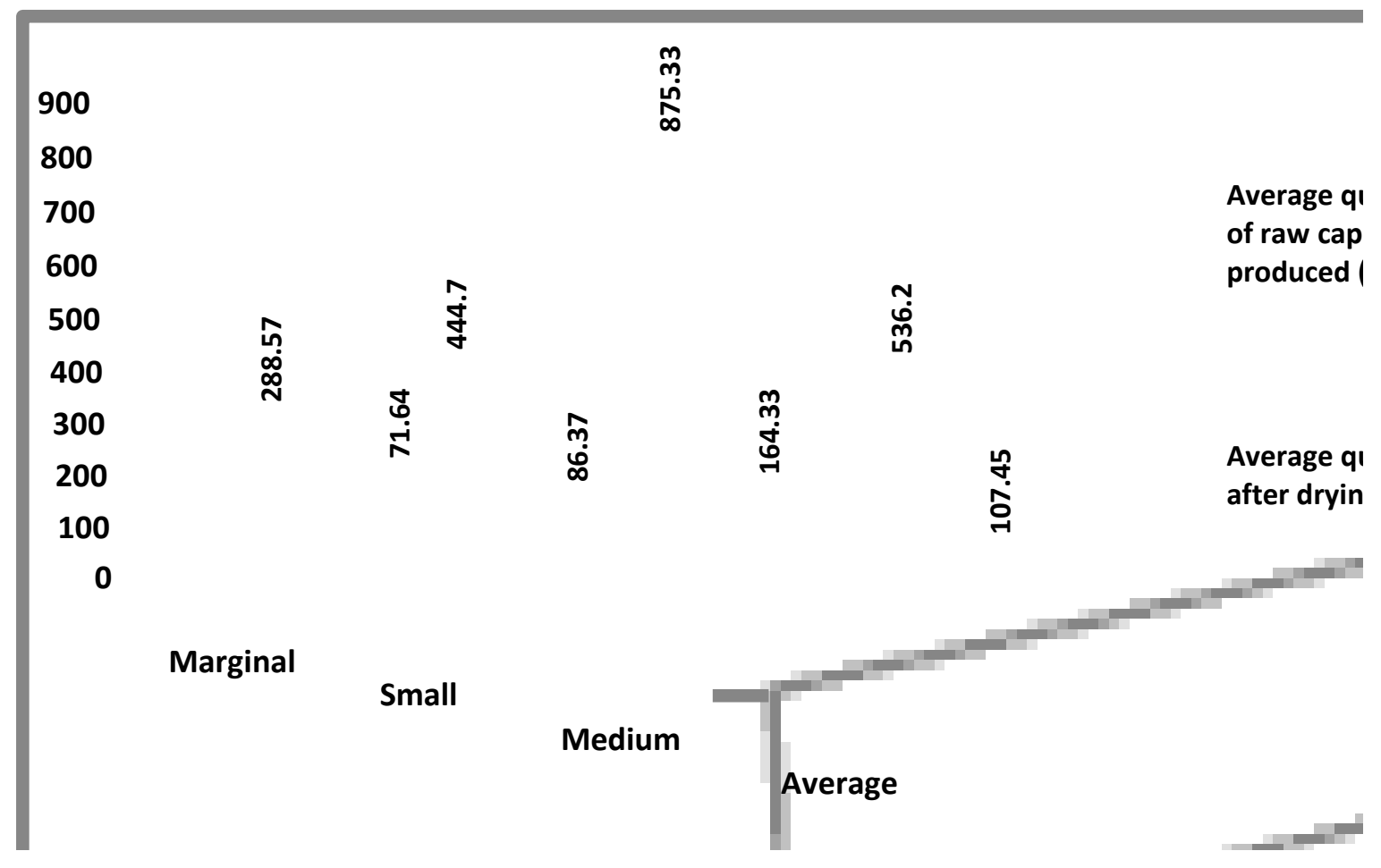


Fig.4 Estimation of post-harvest losses in large cardamom incurred at intermediaries' level

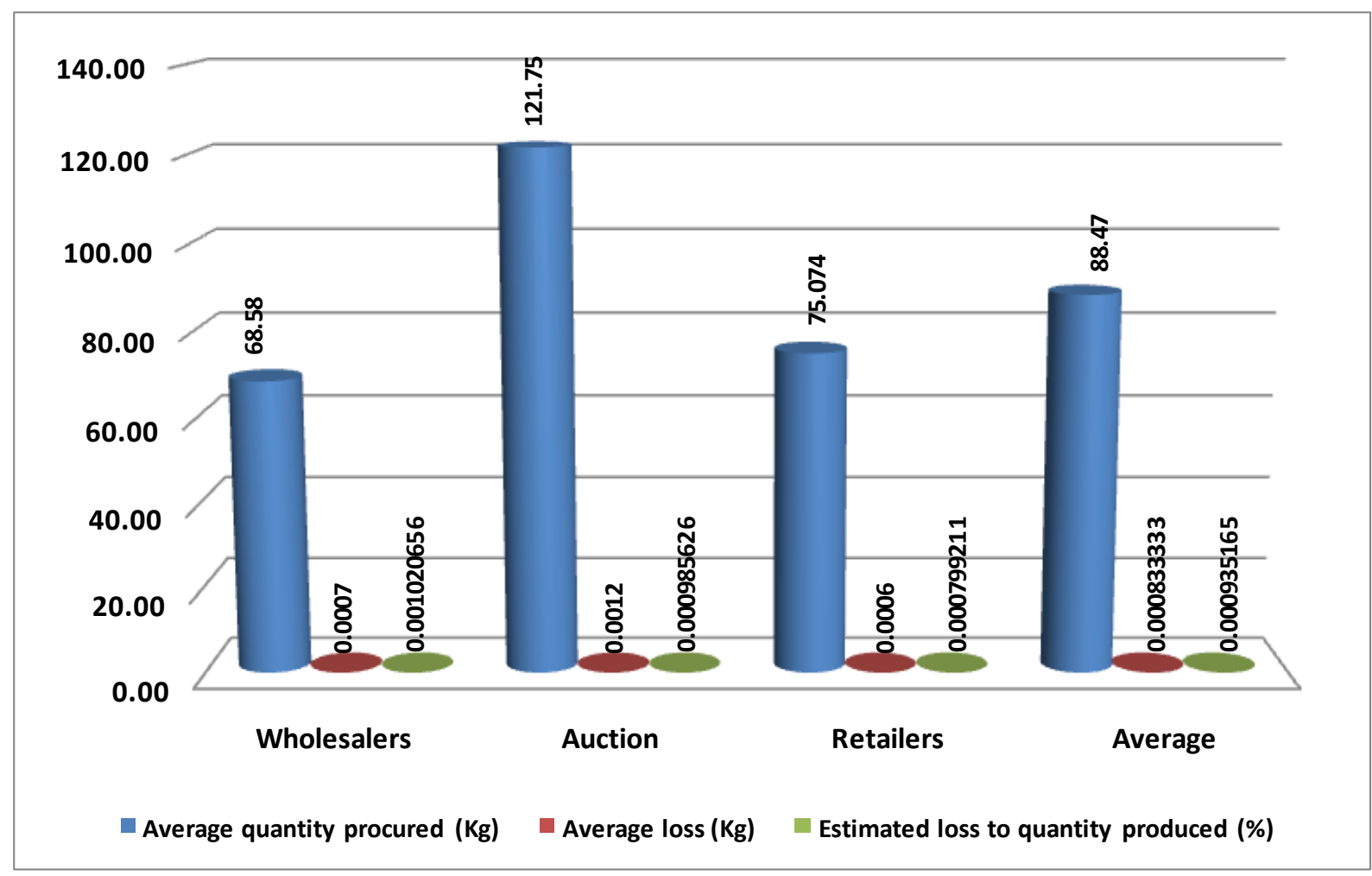

Fig.5 Estimation of post-harvest losses in ginger incurred at farmers' level

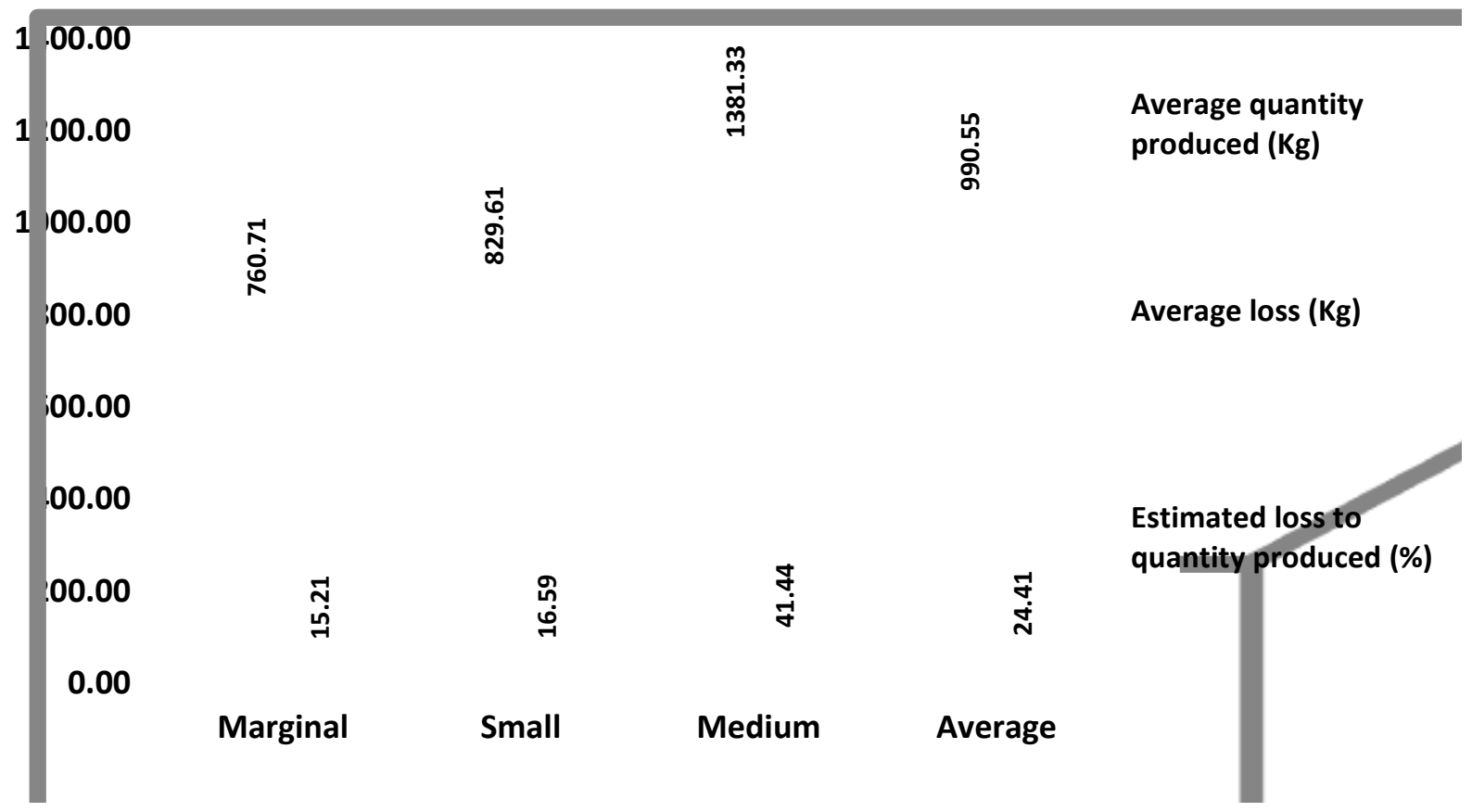


Fig.6 Estimation of post-harvest losses in ginger incurred at intermediaries' level

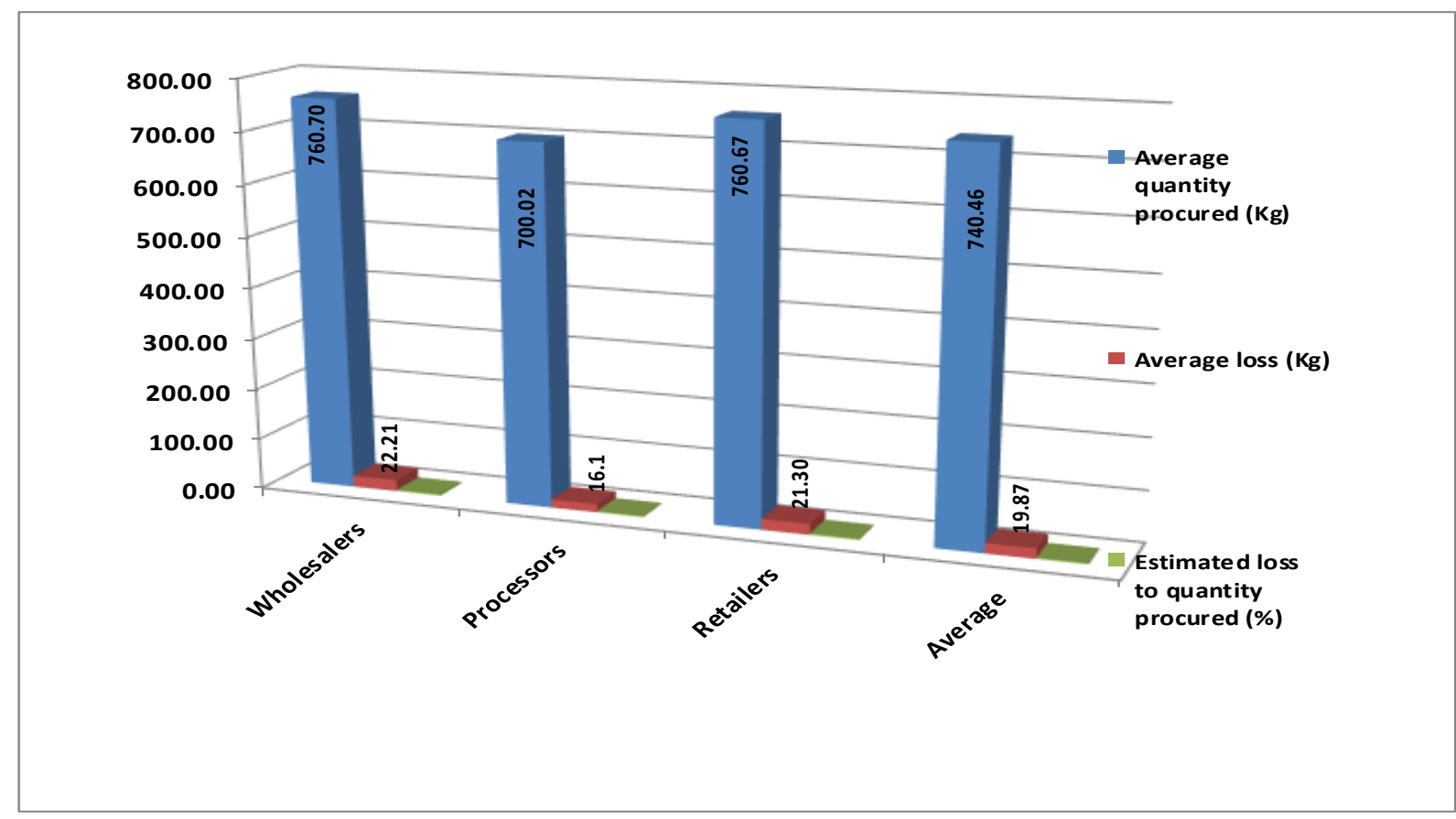

In conclusion, in the assessment of postharvest losses for large cardamom, it was found that no economic loss was involved at farmers' level and the estimated loss at intermediaries' level was found to be very low at every level as large cardamom capsules are sold only after drying. The estimated loss was found to be highest at auction level ( 0.00099 per cent) due to the fact that farmers prefer to sell the produce only when they get satisfactory prices.

In case of ginger, the highest estimated loss was for semi- medium farmers (3.00 per cent), followed by small and marginal farmers (2.00 per cent) each, respectively. At intermediaries' level the highest estimated loss was incurred by wholesalers (3.00 per cent), followed by retailers ( 2.80 per cent) and Processors ( 2.30 per cent), respectively.

\section{References}

Adhikari, P.P. 2016. Cardamom cultivation technology, Agriculture Information and
Communication Center, Hariharbhawan Lalitpur, Nepal.

Analogous. 2018. Statistical Hand of Sikkim Published by Directorate of Economics and Statistics (various issues), Gangtok, Sikkim.

Anonymous. 2017. Marketing strategies for organic produce of Sikkim, A report submitted to Sikkim Organic Mission, Government of Sikkim, Gangtok, CGS National Institute of Agricultural Marketing. Ministry of Agriculture and Farmers Welfare, Kota road, Bambala, Pratap Nagar, Jaipur, India.

Bhutia, P.H., Sharangi, A.B., Lepcha, R. and Yonzone, R. 2017. Post-harvest and value chain management of large cardamom in hills and uplands. International Journal of Chemical Studies. 6(1): 505-511.

Bisht, V.K., Negi, A.K. and Bhandari, A.K. 2011. Ammomum subulatum cardamom: Traditional Phytochemical and Biological Activities - An overview. African Journal of Agriculture Research, 8(24): 5388-5390.

Dhakre, D. S. and Sharma, Amod. 2010. SocioEconomic Development in India. Environment and Ecology. 4(1): 2469-2472. 
Egyir, I.S., Sarpong, D. B. and Obeng-Ofori, D. (2008) Harvest and postharvest baseline study. Policy Planning, Monitoring and Evaluation Directorate, Ministry of Food and Agriculture, Ghana. Pp: 154.

http://apeda.gov.in/apedawebsite/organic/Organic _Products. Assessed on 13 March 2019.

https://www.ifoam.bio/sites/default/files/page/file s/ifoamstandarddraftv1.1_forconsultation_cl ean_new.doc. Assessed on 23 April 2019.

Pongener, Bendangjungla and Sharma, Amod. 2018. Constraints Faced by the Fishery Enterprises: A SWOC Analysis. IJCMAS. 7(5). May: 1595-1603.

Rahman, H., Bujarbaruah, K.M., Srivastava, L.S., Karuppaiyan, R., Avasthe R.K. and Singh, M. 2007. Status of ginger cultivation in Sikkim with special reference to disease management. ICAR Research Complex for NEH Region Sikkim Centre, Tadong, Gangtok.

Sharma, A. and Sharma, Anamika. 2008. Problems faced by the farmers in adoption of improved maize cultivation practices in hills. TJRAR. 8(2): 22-23.

Sharma, Amod. 2011. Economic and Constraints of King Chilli Growers in Dimapur District of Nagaland. Journal of Interacademicia. 15(4): 710-719.

Sharma, Amod. 2012. Inter-state Disparities in Socio-economic Development in North East Region of India. Journal of Agricultural Science. 4(9). September: 236-243.

Sharma, Amod., Kichu, Yimkumba. and Chaturvedi, B. K. 2016. Economics and
Constraints of Pineapple Cultivation in Dimapur District of Nagaland. TJRAR. 16(1). January: 72-75.

Sharma, Amod., Kichu, Yimkumba and Sharma, Pradeep. Kumar. 2018. Sustainable economic analysis and constraints faced by the pineapple growers in Nagaland. Progressive Agriculture. 18(1). February: 27-33.

Shuya, Keviu and Sharma, Amod. 2014. Impact and constraints faced by the borrowers of cooperative bank finance in Nagaland. Economic Affairs. 59(4). October: 561-567.

Shuya, Keviu and Sharma, Amod. 2018. Problems faced by the Borrowers in Utilization and Acquiring of Cooperative Bank Loans in Nagaland. IJED. 14(2). April-June, Pp. 5256.

Walling, Imti. and Sharma, Amod. 2015. Impact of SGRY on beneficiaries and nonbeneficiaries in Dimapur district of Nagaland. TJRAR. 15(2). August: 90-94.

Walling, Imti., Sharma, Amod., Yadav, Mukesh. Kumar., Rajbhar, Arun, Kumar and Kalai, Kankabati. 2017. Impact of Agricultural Technology Management Agency on Rural Economy of Nagaland, India. Plant Archiver. 17(2). October: 1511-1516.

Willer, H. and Lernoud, J. 2018. The world of organic agriculture. Statistics and emerging trends 2018. Research Institute of Organic Agriculture (FiBL), Frick, and IFOAM Organics International, Bonn.

\section{How to cite this article:}

Archana Sharma and Amod Sharma. 2019. Postharvest Losses during the Marketing of Large Cardamon and Ginger Spices Crops in East District of Sikkim. Int.J.Curr.Microbiol.App.Sci. 8(05): 1274-1282. doi: https://doi.org/10.20546/ijcmas.2019.805.145 